\title{
Characterization of the rs2802292 SNP identifies FOXO3A as a modifier locus predicting cancer risk in patients with PJS and PHTS hamartomatous polyposis syndromes
}

Giovanna Forte ${ }^{1}$, Valentina Grossi ${ }^{2,3}$, Valentina Celestini ${ }^{2}$, Giuseppe Lucisano ${ }^{4}$, Marco Scardapane ${ }^{4}$, Dora Varvara ${ }^{2}$, Margherita Patruno ${ }^{2}$, Rosanna Bagnulo ${ }^{2}$, Daria Loconte ${ }^{2}$, Laura Giunti ${ }^{5}$, Antonio Petracca ${ }^{6}$, Sabrina Giglio ${ }^{6}$, Maurizio Genuardi ${ }^{7}$, Fabio Pellegrini ${ }^{4,8}$, Nicoletta Resta $^{2}$ and Cristiano Simone ${ }^{2,3^{*}}$

\begin{abstract}
Background: Hamartomatous polyposis syndromes (HPS) are inherited conditions associated with high cancer risk. They include the Peutz-Jeghers and the PTEN hamartoma tumor syndromes, which are caused by mutations in the LKB1 and PTEN genes, respectively. Estimation of cancer risk is crucial in order to optimize surveillance, but no prognostic markers are currently available for these conditions. Our study relies on a 'signal transduction' hypothesis based on the crosstalk between LKB1/AMPK and PI3K/PTEN/Akt signaling at the level of the tumor suppressor protein FoxO3A. Interestingly, the FOXO3A rs2802292 G-allele was shown to be associated with longevity, reduced risk of aging-related diseases and increased expression of FoxO3A mRNA.
\end{abstract}

Methods: We typed rs 2802292 in 150 HPS unrelated patients and characterized the expression of FoxO3A by quantitative PCR and immunoblot analysis in human intestinal cell lines.

Results: We found a significantly higher risk for malignancies in females and $\Pi T$ genotype carriers compared to patients having at least one G-allele. Subgroup analysis for each HPS syndrome revealed a G-allele-associated beneficial effect on cancer risk occurring mainly in males. Molecular characterization of human intestinal cell lines showed that the G-allele significantly correlated with increased basal expression of FoxO3A mRNA and protein.

Conclusion: Our results suggest an inverse correlation between the protective allele (G) copy number and cancer risk, and might be useful to optimize surveillance in HPS patients. Further investigations are needed to confirm our hypothesis and to ascertain whether differences in therapeutic response exist across genotypes.

Keywords: Hamartomatous polyposis syndromes, PJS, PHTS, FOXO3A, Cancer risk

\section{Background}

Hamartomatous polyposis syndromes (HPS) - PeutzJeghers syndrome (PIS), PTEN hamartoma tumor syndrome (PHTS) and juvenile polyposis syndrome (JPS) - are inherited conditions showing hamartomatous polyp histology and increased risk of cancer during lifetime.

\footnotetext{
* Correspondence: cristianosimone73@gmail.com

${ }^{2}$ Division of Medical Genetics, Department of Biomedical Sciences and Human Oncology (DIMO), Università di Bari "Aldo Moro", Policlinico, Piazza Giulio Cesare 11, 70124 Bari, Italy

${ }^{3}$ National Cancer Institute, IRCCS Oncologico Giovanni Paolo II, 70124 Bari, Italy

Full list of author information is available at the end of the article
}

Hamartomatous polyps originate from uncontrolled proliferation of stromal cells and represent a small fraction of all polyps arising in the GI tract [1].

PJS is an autosomal dominant disease with an estimated prevalence of $1 / 8,300$ to $1 / 200,000$, and is characterized by the presence of mucocutaneous pigmentation, hamartomatous polyps and an increased risk of cancer at different sites (breast, GI tract, gynecological tumors) [2]. PJS is caused by mutations in the $L K B 1$ tumor suppressor gene, which encodes a serine/threonine kinase [3].

PHTS has a prevalence estimate of $1 / 200,000$ and comprises a group of phenotypically diverse rare autosomal 
dominant conditions including Cowden syndrome (CS) and Bannayan-Riley Ruvalcaba syndrome (BRRS) [4]. These are caused by germline mutations in the PTEN tumor suppressor gene, which encodes a phosphatase. Hamartomatous tumors can affect any organ, namely skin, mucosal membranes, GI tract and other organs in CS, and GI tract in BRRS, which is also associated with macrocephaly, lipomatosis, and pigmented macules of the glans penis. PHTS shows an increased risk of malignancies of the breast, colorectum, thyroid, kidney and endometrium [5].

Several reports estimated cancer risk in HPS. PJS and PHTS patients show a time-dependent high risk of malignancies, with females displaying a significantly higher risk than males mainly due to the occurrence of breast and gynecological tumors $[2,4]$.

Estimation of cancer risk is crucial in order to implement risk-reducing measures, including intensive surveillance, lifestyle changes, chemoprevention or even prophylactic surgery. However, there is currently no available marker that can predict which HPS patients will develop a malignancy and the age at which surveillance should be started. Recently, genetic modifiers have been shown to play a role in determining cancer risk in other mendelian tumor syndromes, such as BRCA1/2related breast and ovarian cancer, [6,7] and SNP genotyping could be of help in identifying a 'modifier locus' to predict the risk of cancer in HPS patients.

Our study is based on a 'signal transduction' hypothesis, which relies on the crosstalk between LKB1/AMPK and PI3K/PTEN/Akt signaling at the level of FoxO3A (Figure 1). In particular, LKB1 activates AMPK, which in turn activates FoxO3A, while PTEN inhibits Akt, which in turn inhibits FoxO3A [8]. Recently, it was found that the FOXO3A locus strongly correlates with the longevity phenotype in genetically diverse groups of European and Asian descent [9-13]. Of note, the FoxO3A rs2802292 G-allele (minor allele count/MAF $=0.449 / 978$ ) [14] was shown to be associated with longevity in all populations tested, [9-13] and its copy number correlated with reduced frequency of aging-related diseases, including cancer, in centenarians [9]. At the molecular level, the rs2802292 G-allele displayed significant correlation with increased basal expression of FoxO3A mRNA in muscle biopsies of twins, suggesting that the second intron of the FOXO3A locus, which contains the rs2802292 SNP, may act as a regulatory sequence [15].

These data suggest that the rs2802292 G-allele could enhance the well-known metabolic and anti-aging activities of FOXO3A by increasing gene expression. Indeed, FoxO3A plays a role in proliferation/arrest, survival/ death, metabolism and autophagy, and has been implicated in tumor suppression, regulation of energy metabolism and development in a number of tissues [8]. All

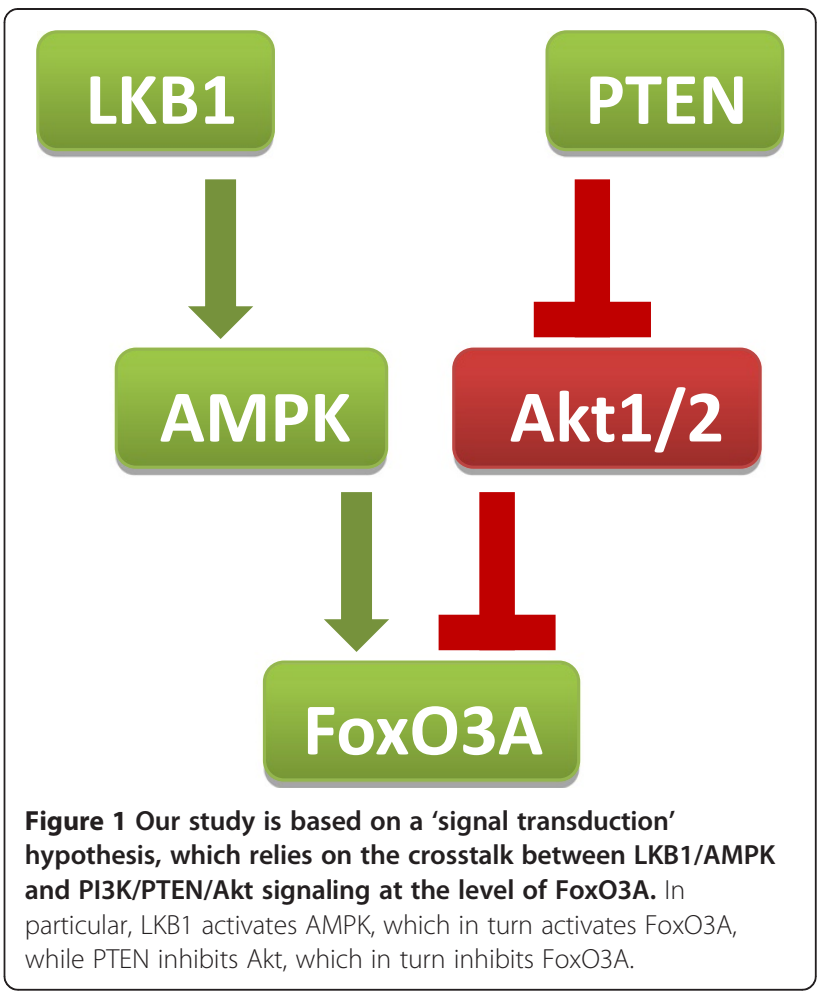

these functions are mediated by the finely tuned activation of a coordinated transcriptional program encompassing genes involved in cell cycle, metabolism, autophagy, stress resistance and cell death [8].

To ascertain whether the positive effect of the rs2802292 G-allele on FoxO3A activity could counteract the detrimental effects of imbalanced AMPK/Akt signals on transformation and cancer progression in PJS and PHTS tissues, we typed this polymorphism in a group of unrelated patients previously characterized for $L K B 1$ or PTEN mutations.

\section{Methods}

\section{Participants}

The FoxO3A rs2802292 SNP was analyzed in 150 HPS unrelated patients with identified mutations in the PTEN (84 patients) or $L K B 1$ (66 patients) genes. PTEN or $L K B 1$ mutation carriers were recruited through various Italian cancer genetics clinics and fulfilled the diagnostic clinical criteria for PJS or PHTS, $[16,17]$ and/or they were carriers of the familial disease-causing mutation. We obtained participants' informed consent approved by the local ethical committees (AOU Policlinico, 70124 Bari, Italy; Meyer University Hospital, 50139 Florence, Italy) for publication of the dataset at recruitment into the study in compliance with international and national data protection laws. The dataset is fully anonymous, as it does not contain any direct or indirect identifier, thus respecting participants' rights to privacy and protecting their identity. 


\section{Cell culture and reagents}

HT-29, Caco-2, LS174T, HCT-116 cells (all from ATCC) were grown in DMEM supplemented with 10\% FBS (HT-29, LS174T and HCT-116) or 20\% FBS (Caco-2), $100 \mathrm{IU} / \mathrm{ml}$ penicillin and $100 \mu \mathrm{g} / \mathrm{ml}$ streptomycin in a humidified incubator at $37^{\circ} \mathrm{C}$ and $5 \% \mathrm{CO} 2$ avoiding confluence at any time.

\section{Genotyping}

Genomic DNA from peripheral blood and cell lines was extracted using QIAsymphony SP/AS instruments (QIAGEN) according to the manufacturer's protocol and quantified on a NanoDROP 2000 spectrophotometer (Thermo Scientific). PCRs were carried out in $25 \mu \mathrm{l}$ reaction mixtures containing 50 ng of genomic DNA, 1X PCR Buffer (Tris-HCl, (NH4)2SO4, $15 \mathrm{mM} \mathrm{MgCl2;}$ $\mathrm{pH}$ 8.7), $200 \mu \mathrm{M}$ dNTPs and $0.5 \mathrm{U}$ HotStarTaq DNA Polimerase (QIAGEN) and the following primers (10 pmol each): FoxO3A rs2802292g/t Fw, cagcttctgagtgacagagtg and FoxO3A rs2802292g/t Rw, ttcttccctagagagcagcag. PCR amplification cycles were carried out at $95^{\circ} \mathrm{C}$ for $15 \mathrm{~min}$ followed by 29 cycles of denaturation at $94^{\circ} \mathrm{C}$ for $1 \mathrm{~min}$, annealing at $60^{\circ} \mathrm{C}$ for $1 \mathrm{~min}$ and extension at $72^{\circ} \mathrm{C}$ for $1 \mathrm{~min}$, and then a final extension at $72^{\circ} \mathrm{C}$ for $10 \mathrm{~min}$ on a GeneAmp PCR System 9700 thermocycler (Applied Biosystems). $5 \mu \mathrm{l}$ of the amplified products were loaded onto $2 \%$ Agarose Standard Low EEO (AB Analitica) in 0.5X TBE and visualized using GelRedTM (Biotium, Hayward, CA). Sequencing products were purified by use of the DyeEx ${ }^{\text {mi }} 2.0$ Spin Kit (QIAGEN, Milan, Italy) and sequenced on an ABI PRISM 310 Genetic Analyzer (Applied Biosystems).

\section{Quantitative real time PCR}

Total RNAs were extracted using TRI Reagent (Sigma). Samples were treated with DNase-1 (Ambion) and retro-transcribed using the High Capacity DNA Archive Kit (Applied Biosystems). PCRs were carried out using the SYBR Green PCR Master Mix on an ABI 7500HT machine (Applied Biosystems). Relative quantification was done using the ddCT (Pfaffl) method. Primer sequences are available upon request.

\section{Immunoblotting analysis}

Immunoblotting analyses were performed according to Cell Signaling's instructions. Briefly, cells were homogenized in $1 \mathrm{X}$ lysis buffer (50 mM Tris- $\mathrm{HCl}$ pH 7.4; $5 \mathrm{mM}$ EDTA; $250 \mathrm{mM} \mathrm{NaCl} ; 0.1 \%$ Triton X-100) supplemented with protease and phosphatase inhibitors (1 mM PMSF; $1.5 \mu \mathrm{M}$ pepstatin $\mathrm{A} ; 2 \mu \mathrm{M}$ leupeptin; $10 \mu \mathrm{g} / \mathrm{ml}$ aprotinin, $5 \mathrm{mM} \mathrm{NaF} ; 1 \mathrm{mM} \mathrm{Na} 3 \mathrm{VO} 4)$. 15 to $20 \mu \mathrm{g}$ of protein extracts from each sample were denatured in $5 \times$ Laemmli sample buffer and loaded into an SDS-polyacrylamide gel for western blot analysis. Western blots were performed using anti- $\beta$-Actin (Sigma) and anti-FoxO3A (Cell Signaling). Western blots were developed with the ECL-plus chemiluminescence reagent (GE Healthcare) as per manufacturer's instructions.

\section{Statistical methods}

Patient characteristics were reported as medians and interquartile range (IR), and frequency and percentages, for continuous and categorical variables, respectively. Characteristics were also stratified according to the presence of malignant tumors, mutation type and genotype, and compared using Pearson's $\chi^{2}$ and MannWhitney $U$ tests for categorical and continuous variables, respectively. To account for potential confounding, presence of malignant tumors was analysed with multivariate logistic regression models and the following covariates were included: gender, age at diagnosis (in years) and genotype (TT and XG). Results were reported as odds ratios (ORs) along with their $95 \%$ confidence intervals $(95 \% \mathrm{CI})$. Adjusted risks for each variable employed in the models were also estimated. Two-sided p-values $<0.05$ were considered statistically significant. All statistical analyses were performed using SAS Statistical Package version 9.3 (SAS Institute, Cary, NC).

\section{Results}

A total of 150 patients were analyzed. Median age at diagnosis was 18 (IR 1-77) years, females were 44.7\%, and patients with $L K B 1$ and PTEN mutations were $56 \%$ and 44\%, respectively. Prevalence of the rs 2802292 G-allele was $45.3 \%$, which is consistent with the MAF previously described for the general population [14].

Overall cancer risk for our sample was 19.7\%. Patient characteristics according to the presence of malignancies (see Table 1 for cancer locations) are shown in Table 2. Patients with and without cancer tended to differ significantly in terms of gender, age at diagnosis and TT

Table 1 Tumor number and location in PJS and PHTS patients

\begin{tabular}{lcc}
\hline & PHTS patients* & PJS patients** \\
\hline Thyroid & 4 & 1 \\
Breast & 3 & 4 \\
Gynecological tract & 2 & 10 \\
Kidney & 2 & 0 \\
Gastrointestinal tract & 1 & 3 \\
CNS & 1 & 0 \\
Other & 1 & 0 \\
Total & 14 & 18 \\
\hline
\end{tabular}

*2 patients with multiple tumors.

**3 patients with multiple tumors. 
Table 2 Patients characteristics according to the presence of malignant tumors

\begin{tabular}{|c|c|c|c|c|}
\hline \multirow[b]{2}{*}{ Variable } & \multirow[b]{2}{*}{ Category } & \multicolumn{2}{|c|}{ Malignant tumors } & \multirow[b]{2}{*}{$\mathrm{p}$-value } \\
\hline & & No & Yes & \\
\hline$n$ & & 106 & 26 & \\
\hline Age & & $\begin{array}{c}31.00 \\
(3.00-78.00)\end{array}$ & $\begin{array}{c}48.00 \\
(13.00-85.00)\end{array}$ & 0.001 \\
\hline Age at diagnosis & & $\begin{array}{c}17.00 \\
(1.00-72.00)\end{array}$ & $\begin{array}{c}24.50 \\
(5.00-77.00)\end{array}$ & 0.0421 \\
\hline \multirow[t]{3}{*}{ Genotype } & GG & $28(26.42)$ & $5(19.23)$ & 0.1062 \\
\hline & TG & $48(45.28)$ & $8(30.77)$ & \\
\hline & $\pi$ & $30(28.30)$ & $13(50.00)$ & \\
\hline \multirow[t]{2}{*}{ Genotype (2 levels) } & $X G$ & $76(71.70)$ & $13(50.00)$ & 0.0344 \\
\hline & $\pi$ & $30(28.30)$ & $13(50.00)$ & \\
\hline \multirow[t]{2}{*}{ Mutation } & $\angle K B 1$ & $56(52.83)$ & $16(61.54)$ & 0.4242 \\
\hline & PTEN & $50(47.17)$ & $10(38.46)$ & \\
\hline \multirow[t]{2}{*}{ Sex } & $\mathrm{F}$ & 39 (36.79) & $17(65.38)$ & 0.0082 \\
\hline & M & $67(63.21)$ & $9(34.62)$ & \\
\hline \multirow[t]{2}{*}{ Benign tumors } & No & $27(25.47)$ & $3(11.54)$ & 0.1287 \\
\hline & Yes & $79(74.53)$ & $23(88.46)$ & \\
\hline \multirow[t]{2}{*}{ G.I. benign tumors } & No & $43(40.57)$ & $4(15.38)$ & 0.0163 \\
\hline & Yes & $63(59.43)$ & $22(84.62)$ & \\
\hline \multirow[t]{2}{*}{ G.I. malignant tumors } & No & $106(100.00)$ & $21(80.77)$ & $<0.0001$ \\
\hline & Yes & $0(0.00)$ & $5(19.23)$ & \\
\hline
\end{tabular}

Data are expressed as medians and interquartile range, and frequency and percentages, for continuous and categorical variables, respectively. $P$ values refer to Pearson's $X^{2}$ and Mann-Whitney $\mathrm{U}$ tests for categorical and continuous variables, respectively.

genotype. Results for case-mix (i.e. gender and age at diagnosis) adjusted analyses are provided in Table 3. A significantly higher risk of malignancies was found for females (OR 3.33, 95\% CI 1.32-8.33; p: 0.011) and TT genotype carriers compared to patients having at least one G-allele (XG) (OR 2.53, 95\% CI 1.01-6.34; p: 0.048). This genotype-associated risk increase was slightly greater in PJS (OR 2.82 95\% CI 0.74-10.81; p: 0.128) than in PHTS (OR 2.14 95\% CI 0.46-9.93; p: 0.332) (Tables 4 and 5). Furthermore, females carrying at least one G-allele (XG) showed a cancer risk of $28 \%$

Table 3 Multivariate logistic regression model for the presence of malignant tumors

\begin{tabular}{lccc}
\hline Parameter & Label & OR $\mathbf{( 9 5 \% ~ C l )}$ & P value \\
\hline Sex & M VS F & $0.30(0.12-0.76)$ & 0.0114 \\
Genotype (2 levels) & TT VS XG & $2.53(1.01-6.34)$ & 0.0484 \\
Age at diagnosis & & $1.02(0.99-1.04)$ & 0.1797 \\
\hline
\end{tabular}

Model is adjusted for gender, age at diagnosis (in years) and genotype (2 levels).
Table 4 Multivariate logistic regression model for the presence of malignant tumors in PJS patients

\begin{tabular}{|c|c|c|c|}
\hline Parameter & Label & OR $(95 \% \mathrm{Cl})$ & $P$ value \\
\hline Sex & M VS F & $0.23(0.06-0.94)$ & 0.0407 \\
\hline Genotype (2 levels) & TT VS XG & $2.82(0.74-10.71)$ & 0.1285 \\
\hline Age at diagnosis & & $1.02(0.97-1.06)$ & 0.4816 \\
\hline
\end{tabular}

(95\% CI 15-44\%), which increased to 35\% (95\% CI 17 $58 \%$ ) for TT females. Of note, only 6\% (95\% CI 2-16\%) of XG males had cancer, while the percentage rose to $25 \%$ (95\% CI 12-47\%) for TT male carriers. Subgroup analysis for each syndrome revealed that the G-alleleassociated beneficial effect on cancer risk occurs mainly in HPS males [PJS males with cancer: XG 7\% (95\% CI $1-27 \%$ ) vs TT $22 \%$ (95\% CI 5-62\%); PHTS males with cancer: XG $4 \%$ (95\% CI $0-27 \%)$ vs TT $28 \%$ (95\% CI 9-59\%)]. Of note, PJS females carrying the TT genotype were the subgroup with the highest cancer rate $[49 \%$ (95\% CI 21-77)]. This latter result suggests an inverse correlation between the copy number of the protective allele $(G)$ and the risk of cancer, which would be consistent with the reduced frequency of aging-related diseases, including cancer, observed in centenarians [9].

To get insight into the molecular mechanism possibly explaining the beneficial effect of the rs2802292 Gallele, we measured FoxO3A mRNA and protein levels in human intestinal cell lines. Based on our results, cells carrying the GG genotype (HCT-116, Caco-2) showed significantly higher expression of FoxO3A mRNA and protein compared to cells with the TT genotype (HT29, LS174T) (Figure 2). These data are in agreement with the analysis performed in muscle biopsies of 190 twins indicating that the rs $2802292 \mathrm{G}$-allele was associated with increased basal expression of FoxO3A mRNA [15].

\section{Discussion}

None of the other parameters (mutation type, presence of benign tumors and age at diagnosis) significantly

Table 5 Multivariate logistic regression model for the presence of malignant tumors in PHTS patients

\begin{tabular}{lccc}
\hline Parameter & Label & OR $(\mathbf{9 5 \%} \mathbf{C l})$ & P value \\
\hline Sex & M VS F & $0.52(0.11-2.42)$ & 0.4038 \\
Genotype (2 levels) & TT VS XG & $2.14(0.46-9.93)$ & 0.3317 \\
Age at diagnosis & & $1.02(0.99-1.06)$ & 0.1917 \\
\hline
\end{tabular}

The model is adjusted for gender, age at diagnosis (in years) and genotype (2 levels). 


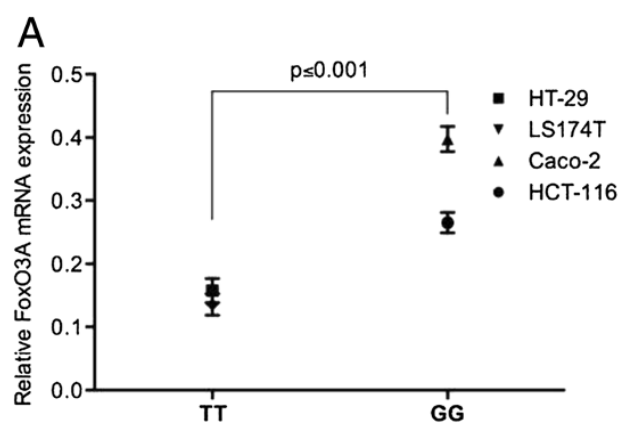

B

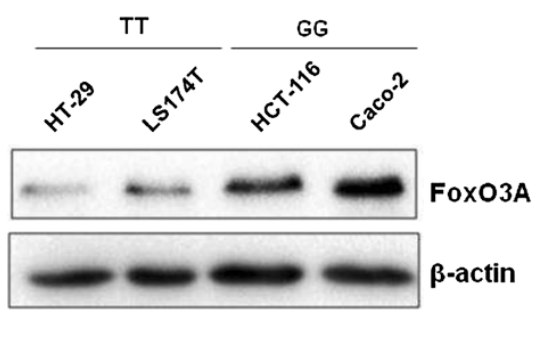

Figure 2 GG genotype is associated with increased expression of FoxO3A both at the mRNA and protein level. HT-29, LS174T, HCT-116 and Caco-2 human intestinal cells were typed for the rs2802292 polymorphism and then analyzed by quantitative real-time PCR (A) and immunoblotting (B) to measure FoxO3A mRNA and protein expression. $\beta$-Actin was used as a loading control.

influenced cancer risk in our cohort. These results are of high interest because various research groups throughout the world reported cancer risk estimates of up to and over $80 \%$ for HPS patients by age $70[2,4]$. Based on our data, we speculate that HPS subjects carrying a GG genotype (which supposedly make up around $20 \%$ of the overall HPS population) are less likely to develop cancer or tend to be affected at an advanced age, while TT subjects develop malignancies earlier in life and TG individuals show an intermediate phenotype. Indeed, our 'signal transduction' hypothesis, which proposed FoxO3A as the crossroad of the HPS pathways LKB1/AMPK and PI3K/PTEN/Akt (Figure 1), is supported by our finding that the GG genotype is associated with increased expression of FoxO3A both at the mRNA and protein level (Figure 2). Regulation of FoxO3A protein expression and localization is crucial for cancer progression and treatment. Indeed, FoxO3A is downregulated in several neoplasms, [18] and inducing increased FoxO3A expression levels is often sufficient to trigger its transcriptional program in cancer cells leading to cell cycle arrest, metabolic regulation and cell death [19].

\section{Conclusions}

Given the relatively small sample size and the crosssectional design of the study, we cannot exclude the possibility of uncontrolled biases and residual confounding, which is why this hypothesis needs to be confirmed on a higher number of patients and on different populations, as well as through prospective studies. These investigations will also be crucial to ascertain whether differences exist in terms of therapeutic response across genotypes and if mortality is influenced by the rs 2802292 allele in HPS subjects. Indeed, FoxO3A, which is a well-known tumor suppressor gene, has emerged as a key downstream effector of various drugs used in tumor treatments, such as p38 inhibitors, cisplatin, paclitaxel, doxorubicin, imatinib, PI3K-Akt inhibitors, EGFR/HER2 inhibitors, and ionizing radiation [8].

\section{Abbreviations}

HPS: Hamartomatous polyposis syndromes; PJS: Peutz-Jeghers syndrome; PHTS: PTEN hamartoma tumor syndrome; JPS: juvenile polyposis syndrome; CS: Cowden syndrome; BRRS: Bannayan-Riley Ruvalcaba syndrome.

\section{Competing interests}

The authors declare that they have no competing interests.

\section{Authors' contributions}

GF, VG, VC, RB, DL, LG, DV, MP, and AP acquisition of data, technical support. GL and MS statistical analysis; analysis and interpretation of data. $S G, M G$, FP, and NR critical revision of the manuscript for important intellectual content. CS study concept and design, analysis and interpretation of data; drafting of the manuscript; study supervision. All authors read and approved the final version.

\section{Acknowledgements}

We thank Dr Francesco Paolo Jori for his helpful discussion during the preparation of the manuscript and editorial assistance, Drs Alessia Peserico and Tugsan Tezil for technical assistance.

\section{Funding}

V.G. is supported by an Italian Association for Cancer Research (AIRC) fellowship. This study was partially supported by FIRB - FUTURO IN RICERCA RBFR12VP3Q_003 (to C.S.) from the Italian MIUR.

\section{Author details}

'Cancer Genetics Laboratory, IRCCS 'De Bellis', Castellana Grotte, 70013 Bari, Italy. ${ }^{2}$ Division of Medical Genetics, Department of Biomedical Sciences and Human Oncology (DIMO), Università di Bari "Aldo Moro", Policlinico, Piazza Giulio Cesare 11, 70124 Bari, Italy. ${ }^{3}$ National Cancer Institute, IRCCS Oncologico Giovanni Paolo II, 70124 Bari, Italy. ${ }^{4}$ Unit of Biostatistics, DCPE, Fondazione Mario Negri Sud, Santa Maria Imbaro, 66030 Chieti, Italy. ${ }^{5}$ Medical Genetics Unit, Meyer University Hospital, 50139 Florence, Italy. ${ }^{6}$ Dipartimento di Scienze Biomediche, Sperimentali e Cliniche, University of Florence, 50139 Florence, Italy. ${ }^{7}$ Institute of Medical Genetics, "A. Gemelli" School of Medicine, Catholic University, 00168 Rome, Italy. ${ }^{8}$ Unit of Biostatistics, Scientific Institute Casa Sollievo della Sofferenza, San Giovanni Rotondo, 71013 Foggia, Italy.

Received: 15 April 2014 Accepted: 2 September 2014 Published: 11 September 2014 


\section{References}

1. Gammon A, Jasperson K, Kohlmann W, Burt RW: Hamartomatous polyposis syndromes. Best Pract Res Clin Gastroenterol 2009, 23:219-231.

2. Resta N, Pierannunzio D, Lenato GM, Stella A, Capocaccia R, Bagnulo R, Lastella P, Susca FC, Bozzao C, Loconte DC, Sabbà C, Urso E, Sala P, Fornasarig M, Grammatico P, Piepoli A, Host C, Turchetti D, Viel A, Memo L, Giunti L, Stigliano V, Varesco L, Bertario L, Genuardi M, Lucci Cordisco E, Tibiletti MG, Di Gregorio C, Andriulli A, Ponz de Leon M, et al: Cancer risk associated with STK11/LKB1 germline mutations in Peutz-Jeghers syndrome patients: results of an Italian multicenter study. Dig Liver Dis 2013, 45:606-611.

3. Resta N, Simone C, Mareni C, Montera M, Gentile M, Susca F, Gristina R, Pozzi S, Bertario L, Bufo P, Carlomagno N, Ingrosso M, Rossini FP, Tenconi R, Guanti G: STK11 mutations in Peutz-Jeghers syndrome and sporadic colon cancer. Cancer Res 1998, 58:4799-4801.

4. Bubien V, Bonnet F, Brouste V, Hoppe S, Barouk-Simonet E, David A, Edery P, Bottani A, Layet V, Caron O, Gilbert-Dussardier B, Delnatte C, Dugast C, Fricker JP, Bonneau D, Sevenet N, Longy M, Caux F, French Cowden Disease Network: High cumulative risks of cancer in patients with PTEN hamartoma tumour syndrome. J Med Genet 2013, 50:255-263.

5. Tan MH, Mester JL, Ngeow J, Rybicki LA, Orloff MS, Eng C: Lifetime cancer risks in individuals with germline PTEN mutations. Clin Cancer Res 2012, 18:400-407.

6. Wang X, Pankratz VS, Fredericksen Z, Tarrell R, Karaus M, McGuffog L, Pharaoh PD, Ponder BA, Dunning AM, Peock S, Cook M, Oliver C, Frost D, EMBRACE, Sinilnikova OM, Stoppa-Lyonnet D, Mazoyer S, Houdayer C, GEMO, Hogervorst FB, Hooning MJ, Ligtenberg MJ, HEBON, Spurdle A, Chenevix-Trench G, kConFab, Schmutzler RK, Wappenschmidt B, Engel C, Meindl $A$, et al: Common variants associated with breast cancer in genome-wide association studies are modifiers of breast cancer risk in BRCA1 and BRCA2 mutation carriers. Hum Mol Genet 2010, 19:2886-2897.

7. Gaudet MM, Kuchenbaecker KB, Vijai J, Klein RJ, Kirchhoff T, McGuffog L, Barrowdale D, Dunning AM, Lee A, Dennis J, Healey S, Dicks E, Soucy P, Sinilnikova OM, Pankratz VS, Wang X, Eldridge RC, Tessier DC, Vincent D, Bacot F, Hogervorst FB, Peock S, Stoppa-Lyonnet D, KConFab Investigators, Peterlongo P, Schmutzler RK, Nathanson KL, Piedmonte M, Singer CF, Thomassen M, et al: Identification of a BRCA2-specific modifier locus at 6 p24 related to breast cancer risk. PLoS Genet 2013, 9:e1003173.

8. Chiacchiera F, Simone C: The AMPK-FoxO3A axis as a target for cancer treatment. Cell Cycle 2010, 9:1091-1096.

9. Willcox BJ, Donlon TA, He Q, Chen R, Grove JS, Yano K, Masaki KH, Willcox DC, Rodriguez B, Curb JD: FOXO3A genotype is strongly associated with human longevity. Proc Natl Acad Sci U S A 2008, 105:13987-13992.

10. Flachsbart F, Caliebe A, Kleindorp R, Blanché $H$, von Eller-Eberstein $H$, Nikolaus S, Schreiber S, Nebel A: Association of FOXO3A variation with human longevity confirmed in German centenarians. Proc Natl Acad Sci U S A 2009, 106:2700-2705.

11. Anselmi CV, Malovini A, Roncarati R, Novelli V, Villa F, Condorelli G, Bellazzi $R$, Puca AA: Association of the FOXO3A locus with extreme longevity in a southern Italian centenarian study. Rejuvenation Res 2009, 12:95-104.

12. Pawlikowska L, Hu D, Huntsman S, Sung A, Chu C, Chen J, Joyner AH, Schork NJ, Hsueh WC, Reiner AP, Psaty BM, Atzmon G, Barzilai N, Cummings SR, Browner WS, Kwok PY, Ziv E, Study of Osteoporotic Fractures: Association of common genetic variation in the insulin/IGF1 signaling pathway with human longevity. Aging Cell 2009, 8:460-472.

13. Li Y, Wang WJ, Cao H, Lu J, Wu C, Hu FY, Guo J, Zhao L, Yang F, Zhang YX Li W, Zheng GY, Cui H, Chen X, Zhu Z, He H, Dong B, Mo X, Zeng Y, Tian $\mathrm{XL}$ : Genetic association of FOXO1A and FOXO3A with longevity trait in Han Chinese populations. Hum Mol Genet 2009, 18:4897-4904.

14. 1000 Genomes Project Consortium, Abecasis GR, Auton A, Brooks LD, DePristo MA, Durbin RM, Handsaker RE, Kang HM, Marth GT, McVean GA: An integrated map of genetic variation from 1,092 human genomes. Nature 2012, 491:56-65.

15. Banasik K, Ribel-Madsen R, Gjesing AP, Wegner L, Andersson A, Poulsen P, Borglykke A, Witte DR, Pedersen O, Hansen T, Vaag A: The FOXO3A rs2802292 G-allele associates with improved peripheral and hepatic insulin sensitivity and increased skeletal muscle-FOXO3A mRNA expression in twins. Clin Endocrinol Metab 2011, 96:E119-E242.

16. Eng C: Will the real Cowden syndrome please stand up: revised diagnostic criteria. J Med Genet 2000, 37:828-830.
17. Riegert-Johnson D, Gleeson FC, Westra W, Hefferon T, Wong Kee Song LM, Spurck L, Boardman LA: Peutz-Jeghers Syndrome. In Cancer Syndromes. Edited by Riegert-Johnson DL, Boardman LA, Hefferon T, Roberts M. Bethesda, MD: National Center for Biotechnology Information (US); 2008. Available online. Accessed 31-03-14.

18. Myatt SS, Lam EW: The emerging roles of forkhead box (Fox) proteins in cancer. Nat Rev Cancer 2007, 7:847-859.

19. Xinbo Z, Naimei T, Hadden TJ, Rishi AK: Akt, FoxO and regulation of apoptosis. Biochim Biophys Acta Mol Cell Res 2011, 1813:1978-1986.

doi:10.1186/1471-2407-14-661

Cite this article as: Forte et al.: Characterization of the rs2802292 SNP identifies $F O X O 3 \mathrm{~A}$ as a modifier locus predicting cancer risk in patients with PJS and PHTS hamartomatous polyposis syndromes. BMC Cancer 2014 14:661.

\section{Submit your next manuscript to BioMed Central and take full advantage of:}

- Convenient online submission

- Thorough peer review

- No space constraints or color figure charges

- Immediate publication on acceptance

- Inclusion in PubMed, CAS, Scopus and Google Scholar

- Research which is freely available for redistribution 